\title{
A Review on Recently Developed Technologies for Weed Recognition and Herbicide Application based on Digital Image Processing
}

\author{
Pankaj Malkani*, K. R. Asha, Atish Sagar, Abhinav Dubey, \\ AkshayKumar Singh and Prashant Singh \\ Department of Agricultural Engineering, ICAR-Indian Agricultural Research Institute, \\ New Delhi-110012, India
}

\section{Keywords \\ SSWM, Weed management, Crop- \\ Weed \\ discrimination, \\ Image processing, \\ smart herbicide \\ applicator \\ Article Info \\ Accepted: \\ 07 November 2019 \\ Available Online: \\ 10 December 2019}

\section{A B S T R A C T}

Weed competes with a crop for nutrition, soil and water and, reduces its yields drastically. Conventional methods i.e. manual, mechanical and chemical mean have some limitations in controlling weeds. With the advancement in electronics and computers, Site-Specific Weed Management (SSWM) can provide a solution for precise weeds management. SSWM technologies with basic components and functions are described. SSWM consists of 3 basic processes i.e. image sensing, cropweed discrimination, and chemical application. Digital image processing plays a crucial role in crop-weed discrimination and fascinates chemical applications.

\section{Introduction}

Weed control is a serious issue in the agricultural production system. It drastically reduces crop yield via competition for natural resources i.e. sunlight, water and nutrients (Ozlüoymak, et al., 2019). Various methods for controlling weeds i.e. manual, mechanical and chemical were used generally. Manual weeding methods were tedious, timeconsuming and expensive. Mechanical methods using intercultural tools are effective only for inter-row weeding. Chemical methods are wieldy used; these are effective for both intra row and inter-row weeding. But the method involves thorough field coverage which nowadays contaminating natural resources i.e. soil, environment, and water (Savci, 2012) and affecting human and animal health. Applying chemicals to only weed patches using site-specific weed management (SSWM) technologies can provide an effective and better solution. Real-time digital image processing integrated with spot herbicide applicator technology can save $75 \%$ herbicide (Yang et al., 2003), 69.5\% savings (Loghavi and Mackvandi, 2008) as compared to the conventional chemical method. SSWM 
involves a three-step process i.e. image acquisition, digital image processing, and herbicide application. Ground-based sensing i.e. optical imaging from the ground has the ability for providing higher spatial resolution, real-time data processing over airborne remote sensing is not suitable for smaller areas because of its lower spatial resolution. This review paper discusses a general overview of the complete process of SSWM and provides recent technologies based upon the above process.

\section{Section I: Components of real time herbicide applicator}

There are 3 steps for the complete process as mentioned earlier. Field image acquisition, crop - weed discrimination and herbicide applicator technology.

General components of real time herbicide technology

Image acquisition- Cameras

Digital Image Processing- Computer, microcontroller and image processing software

Smart spraying system- Tank, solenoid valve, sprays nozzles mounted on boom, microcontroller, and pump with motor.

Other accessories : Global positioning system (GPS) integrated with camera, vehicle.

\section{Working of smart herbicide application system}

A real-time smart application system applies herbicides to the weed patches without harming the crops using a machine vision system. It consisted of sensors which measure crop characteristic 'on the go'. Based on the information collected, a microprocessor processes the information and calculates the needs for inputs and transfers it to the controller system, which delivers the herbicides to the location measured by the sensors. The basic components of a complete herbicide applicator were discussed in section I. The other one is the off-road vehicle consisting of a Global positioning system (GPS) integrated with cameras. The entire system is mounted on an off-road vehicle such as a tractor, self- propelled machine or autonomous vehicles. As the machine moves over terrain, cameras mounted in it will capture the field images which will go to the computer having image processing software like MATLAB, Image Studio Lite, etc., where the image will be processed and the weed will be segmented out from the soil and crop.

The GPS integrated with the camera will provide the location of weed coordinates. The location of the applicator unit on the vehicle was initially set up by considering total time i.e. image processing and time required for the full opening of the solenoid valve. After receiving the weed signal, the microcontroller actuates the solenoid valve nearer to weed and herbicide would be sprayed on it. Thainimitet al., 2012 had shown the typical layout of herbicide applicator system.

\section{Field image acquisition}

Image sensors are classified based on structure (complementary metal-oxide semiconductors (CMOS) and charge-couple devices (CCD)), spectrum covered (Visible (RGB) and Infrared); multispectral and hyperspectral image sensors. Examples-RGB cameras such as (Kodak, Nikon, Sony, Samsung cameras, etc.), Infrared (InfRec R500), multispectral cameras and hyper-spectral cameras (Delta Tee Enterprises 400-1000nm,). RGB cameras are cheaper, perceive information closer to eyes i.e. visible range and it is easy to interpret. Color-based soil-vegetation 
separation is based upon it. Infrared cameras provide information which our eyes can't perceive, sometimes the information provided is also difficult to interpret. Multispectral cameras provide larger information in continuous bands with a broad range of the spectrum. It has a limited number of bands (310) from ultraviolet, visible and infrared range. Hyper-spectral bands also provide information in ultraviolet, RGB as well as infrared range, but in a narrow range, continuous bands, the number of bands are much more than multispectral i.e. (few 1001000), appropriate bands can be used to distinguish crop, weed, and soil.

\section{Digital image processing for crop weed discrimination}

Digital image processing provides an efficient approach for segmenting crop-soil and weed images acquired from the cameras. It generally follows a four-step procedure for crop-weed discrimination i.e. pre-processing, vegetation segmentation, feature extraction, and classification. In this image taken from the cameras were preprocessed for removing noise, resizing and image enhancement. Then a basic threshold-based segmentation process for separating green plant using the excessive green index, normalized difference index, etc., were performed for creating vegetation segmented regions. This will go as an input to the next step, where suitable features i.e. biological morphology, visual texture, and spectral features were extracted from the vegetated segment region. After this vegetated segmented region is classified by performing thresholding techniques on the obtained binary image, another approach for classification except thresholding is a machine vision-based learning algorithm i.e. Artificial Neural Network, Principle Component Analysis, etc. which automatically extracts features from vegetated segment regions and classified it into groups (Fig. 1 and 2).

\section{Smart herbicide spraying system}

The spraying control system consisted of a tank, solenoid valve, sprays nozzles mounted on boom, microcontroller, and pump with motor. The microcontroller receives the response from the computer about the resulting processed image. If the classification steps results, output as a weed. The microcontroller provides an open signal to the solenoid valves near to the weed. Weeds spatial coordinates were obtained from the Global Positioning System (GPS) integrated with the camera. Then a continuously operated pump will supply the chemicals to the nozzles in near to weed patch and spraying will be done (Blue river technology). In some machine's applicator is provided with a moving mechanism in the lateral direction, that reaches to weed location and applies a jet to the weed patches (Eco-robotix). The typical components of smart herbicide spraying system are shown in Figure 3 (Sabanci and Aydin, 2017).

\section{Advance technologies in herbicide application}

Tian et al., (2000) developed a site-specific precision sprayer based on machine vision. The system hardware consisted of cameras, portable computer, 16-bit controller, solenoid valves, speed sensor, and high-speed CX-100 frame grabber. The prototype system used on/off control and a constant flow rate through each nozzle for savings the herbicides. The system was kept ON when the weed density was above the threshold of $1.5 \%$ weed leaf coverage. The current system design could save about $48 \%$ herbicide. The image processing time and on/off spray decision time was $0.37 \mathrm{~s}$ and $0.037 \mathrm{~s}$.

Tangwongkit et al., (2006) developed a realtime, variable rate herbicide applicator using machine vision system for performing inter- 
row weeding in sugarcane field. The components of sprayer were mounted on tractors and are consisted of wheel speed sensor, PWM circuit, web camera and controller (notebook computer), white plastic cover structure for light control, spray-boom with adjustable height and nozzle spacing, fan type nozzles (2 types), a 100- liter capacity tank, 2-support wheels for the rear frame, and a 12-volt DC electrical pump having maximum flow rate $(3.785 \mathrm{l} / \mathrm{min})$ at an operating pressure of $275.8 \mathrm{kPa}$. The software developed could be reprogrammed and the threshold levels could be adjusted according to the user preference. The sprayer was tested for 5 operational speeds; the prototype could spray on green targets correctly. The error of green color output from image processing was about $0.31 \%$ at SD +0.25 . The application flow rate accuracy was about $91.7 \%$. The applicator could save $20.6 \%$ herbicides over uniform application rate from 7091 to 5631 at $0.77 \mathrm{~ms}^{-1}$.

For spot applications of agrochemicals in wild blueberry fields, Zaman et al., 2011 developed a real-time variable rate sprayer. The system consisted of ultrasonic sensors, DICKEY-john Land Manager II controller, flow valve and solenoid valves mounted on a boom. The performance of developed sprayer was evaluated and compared with uniform spraying in two blueberry fields via. Water sensitive papers were stapled to weeds. The percentage area covered with these 2 types of application ranged from $10.01 \%$ to $81.22 \%$ and from $5.39 \%$ to $72.67 \%$ in field 1 and field 2 , respectively. The total lag time of $0.05 \pm 0.003 \mathrm{~s}$ was observed between detecting tall weeds and spraying.

Midtiby et al., (2011) developed and tested a microspraying herbicide (glyphosate) applicator based on smart machine vision. The system consisted of a vision system (CMOS camera, computer), spray system (six nozzles and microcontroller) and a physical microsprayer. The process was tested with maize at a forward speed of $0.5 \mathrm{~ms}-1$ two weed species (scentless mayweed and oilseed rape). The system effectively controls $94 \%$ oilseed rape, $37 \%$ of the scentless mayweed and didn't harm any maize plant. The lower control accuracy for scentless mayweed was due to timing problems of the micro-sprayer control system. It was also concluded that the system was suitable for weed greater than $11 \times 11$ $\mathrm{mm}^{2}$.

Shirzadi et al., 2013 developed and evaluated a real-time, trail- type, site-specific single inter-row herbicide application system based upon machine vision. The weeding control system consisted of an electronic circuit, an image acquisition and processing system, a rotary encoder, spray nozzles, solenoid valves and other hardware. The sprayer output was compared at three levels of weed coverage with traditional (uniform) spraying and no spraying (control).The result indicates that each patch spraying plot used herbicide was proportional to the level of field weed coverage. The target application outcome in $75 \%$ less herbicide consumption compared to the conventional application, with similar effectiveness in weed removal.

Esau et al., 2014 tested an automated chlorothalonil (Bravo) fungicide variable rate sprayer for spot application in a wild blueberry field (Fig. 4). The system consisted of digital cameras, an 8-channel variable rate controller, a LMC, a pocket personal computer (PPC), eight solenoid valves, a servo valve, a flow meter and eight flat fan Teejet- TP8004E nozzles. The VR sprayer saves 9.90 to $51.22 \%$ chemicals. The systems had an overall response time of $0.130 \pm 0.003 \mathrm{~s}$ at a $6 \mathrm{~km} \mathrm{~h}^{-1}$. Tewari et al., (2014) developed a manually operated microcontroller-based roller contacttype herbicide applicator for inter-row crops using machine vision and image processing 
(Fig. 5). The applicator consisted of digital cameras, laptop, microcontroller, proximity switch, DC relay, and solenoid valve. The green parts between rows were categorized as weed and separated from the background via thresholding. The developed applicator was tested for its performance based on percentage herbicide saved and weeding efficiency over constant rate applicator for maize and groundnut. The reduction in herbicide application rate for maize varied from 45.46 $57.2 \%\left(162.33-127.55 \mathrm{lha}^{-1}\right)$ and was observed to be more than $40 \%$ for groundnut. The weeding efficiency was obtained an average $90.16 \%$ and $89.360 \%$ for groundnut and maize respectively.

Gonzalez et al., (2016) developed and evaluated a real-time robotized patch sprayer for site-specific herbicide application. This system can be mounted on any autonomous vehicle such as a tractor. The smart spraying system consisted of 12 high-speed solenoid valve, spray nozzles, led indicator, central direct-injection system, water tank (2001), herbicide container, microcontroller, flow rate measurement sensors motor and battery. The entire system was mounted on a tractor with a laser system for detecting obstacles, RTKGPS for precise location and machine vision for detection of weed. Rate of chemical injection was controlled by direct injection controller. The system performance was measured on a hard surface and it was observed that herbicide savings depend on weed density and its distribution. Herbicide saving closer to $66 \%$ can be achieved on winter crops having low to medium weeds.

Eco-robotics developed a solar operated, fully automated robotic weed killing device for row crops. The system weight was $130 \mathrm{~kg}$ and can be easily carried to the field with tractors. It consisted of a camera, moving mechanism, smaller herbicides tanks mounted on the mechanism, nozzles, navigation system using
GPS and sensors, and solenoid valves. The applicator applies the precise micro-dose amount of chemicals to the individual weeds. The system had the capability to continuously operate for 12 hours per day. It saved 20 times more herbicides as compared to the conventional sprayer.

Ozluoymak et al., (2018) used Lab VIEW programming language to test an automated machine vision-based spray robot for identification, tracking and spraying on artificial weeds.

It consists of a camera $(1280 \times 720$ pixels $)$, a pneumatically controlled spraying unit (STNC, TC 2010-02), air compressor, premix tank, solenoid valve (12 V DC), flat-fan nozzle (110, 0.2-gal min-1 flow rate at $275.79 \mathrm{kPa}$ ). The unit moved back and forth automatically with the optical sensors (Pepperl+Fuchs, GLV18-8-450/115/120) mounted on both ends of the spray device. System performance capability was obtained at 5 speeds and three spraying durations. The results revealed site-specific spraying application saved an average $89.48 \%, 79.98 \%$, and $73.93 \%$ volumes applied respectively in successive spray duration.

Digital image processing in collaboration with smart herbicide applicator technology has the greatest potential to save a huge amount of chemicals. Three steps were performed by SSWM technologies i.e. image sensing, digital image processing for crop -weed discrimination and herbicide application on weeds.

The technologies developed on the basis of these processes had the capability to save about $75 \%$ of chemicals (Shirzadi et al., 2013) and able achieve more than 90\% weeding efficiency. These technologies will help in preventing the environment, soil and groundwater resources for being 
contamination with chemicals. The application cost, labor requirement, and energy will also be saved by the amount of chemical applied.

\section{Way forward}

Various companies like Eco Robotix, John Deere working in collaboration with blue river technology had made successful prototypes, but they are not yet commercialized. Higher costs in initial developing stages and selective crops are some of the reasons. Multiple crops with different weeds type and varieties, variable rate metering based upon weed geometry and characteristic can be a problem need to address in future for the success of the machine.

\section{Acknowledgement}

With greatest honesty, I express my cordial gratitude to Division of Agricultural Engineering, IARI, New Delhi for providing facilities during study.

Fig.1 Layout of the herbicide applicator system (Thainimit et al., 2012)

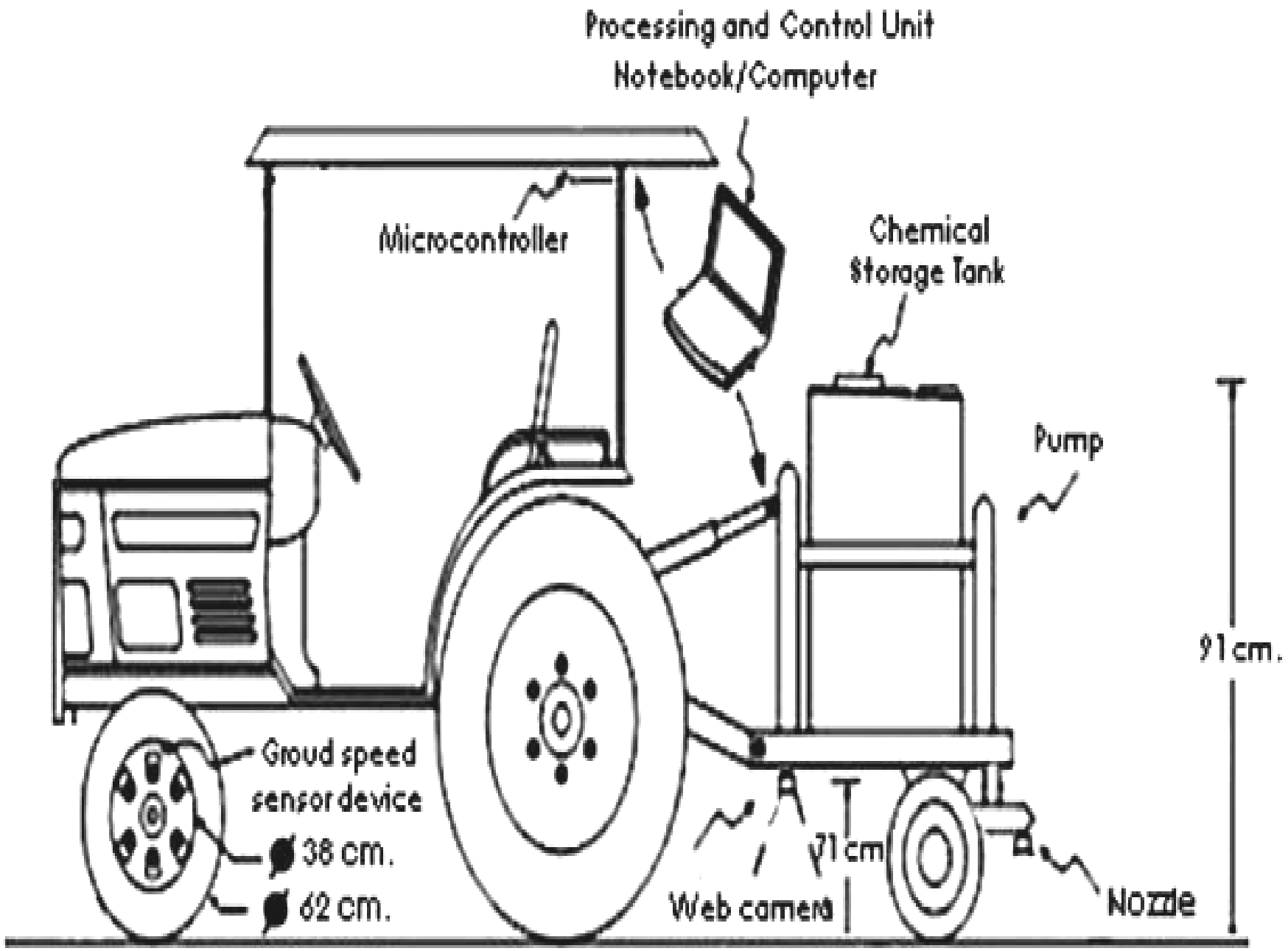


Fig.2 Flow chart of the weed-crop classification system (Weis and Sokefeld, 2010)

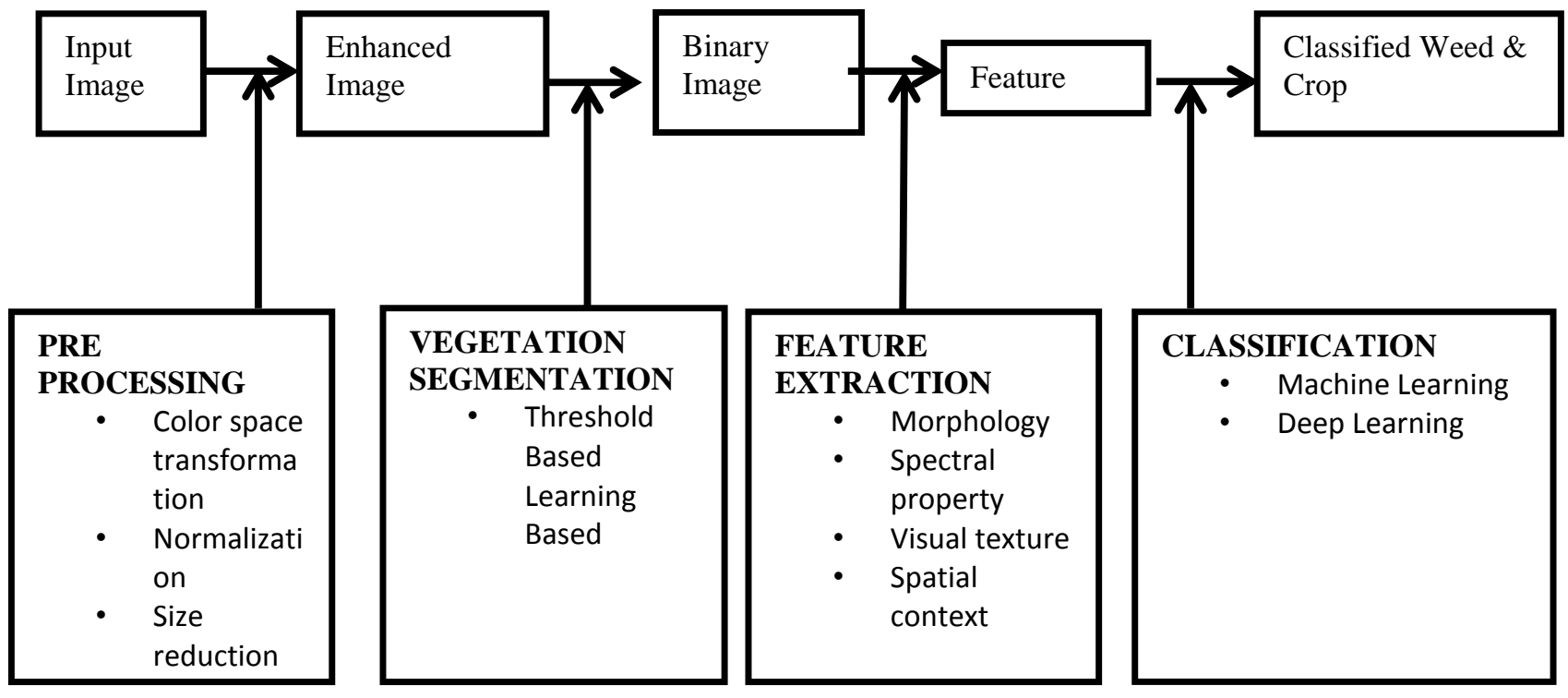

Fig.3 Components of smart spraying system (Sabanci and Aydin, 2017)

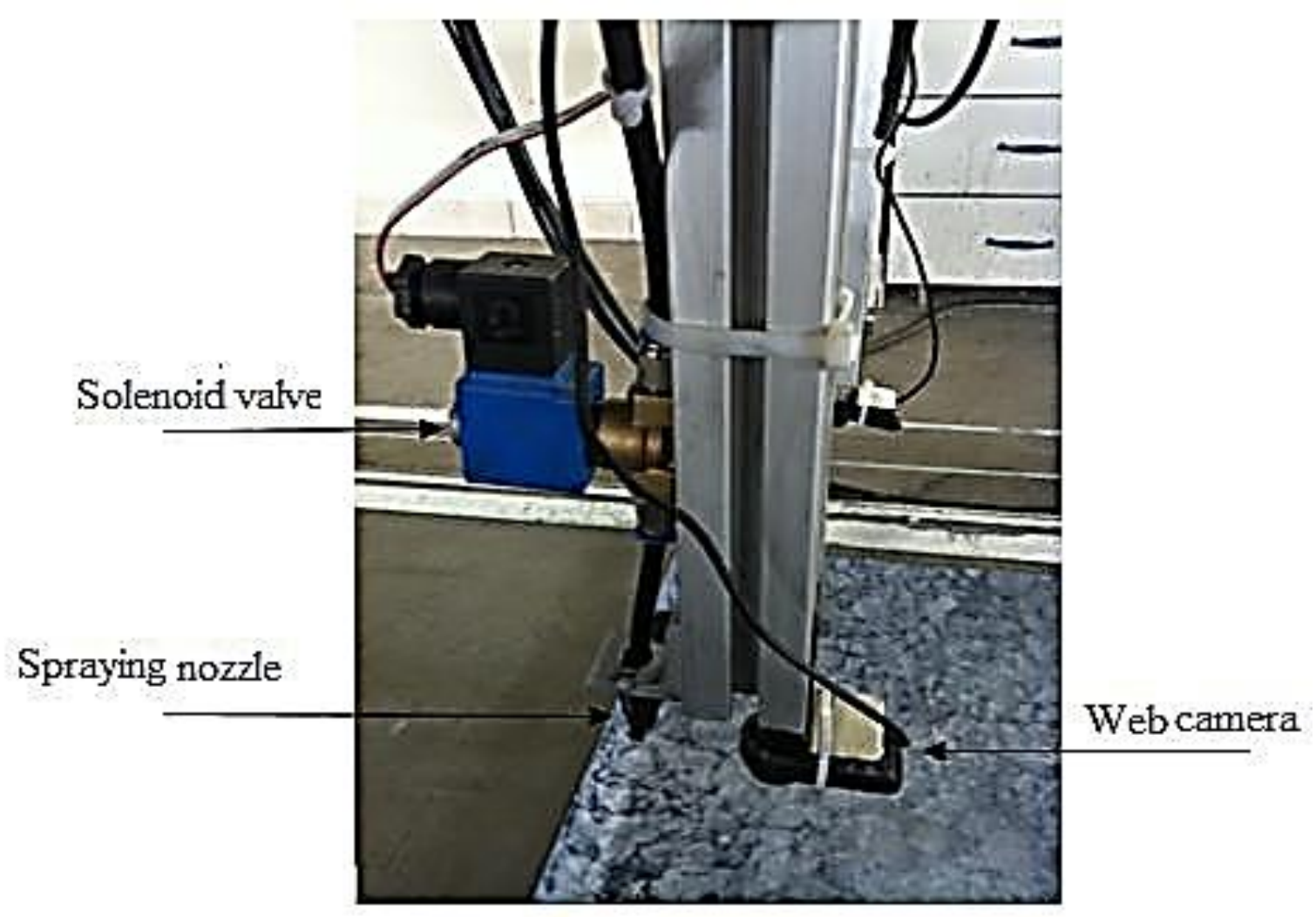


Fig.4 Prototype of variable rate sprayer (Esau et al., 2014)

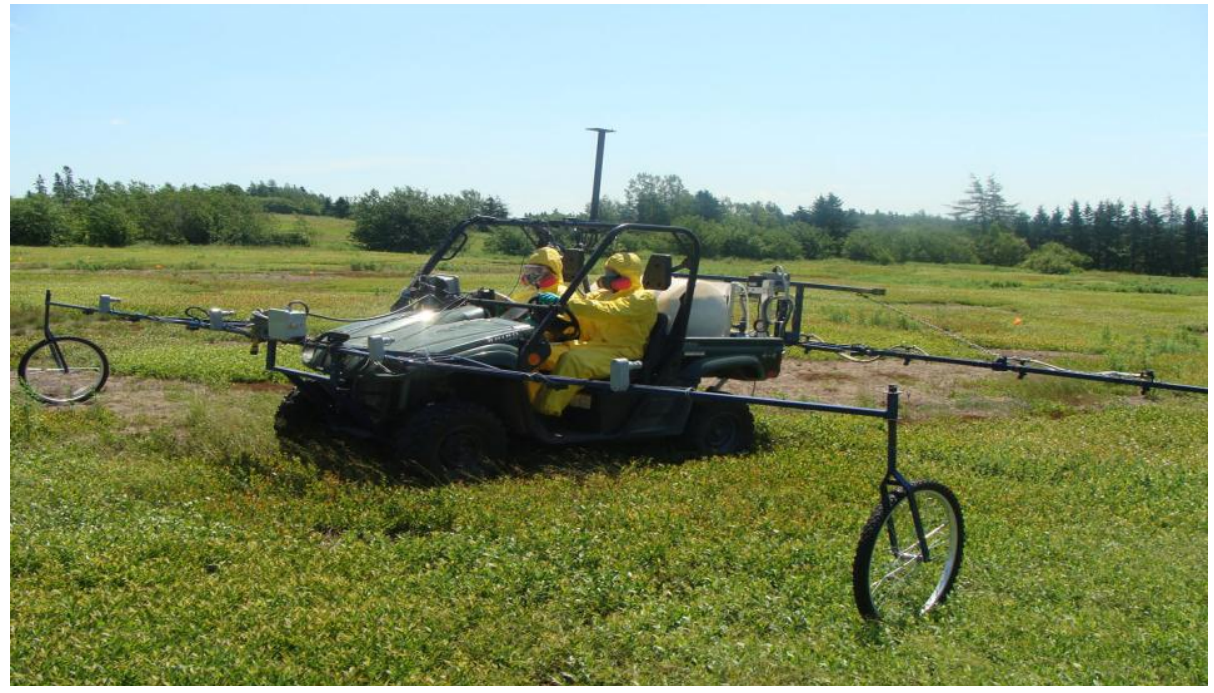

Fig.5 Microcontroller based herbicide applicator (Tewari et al., 2014)

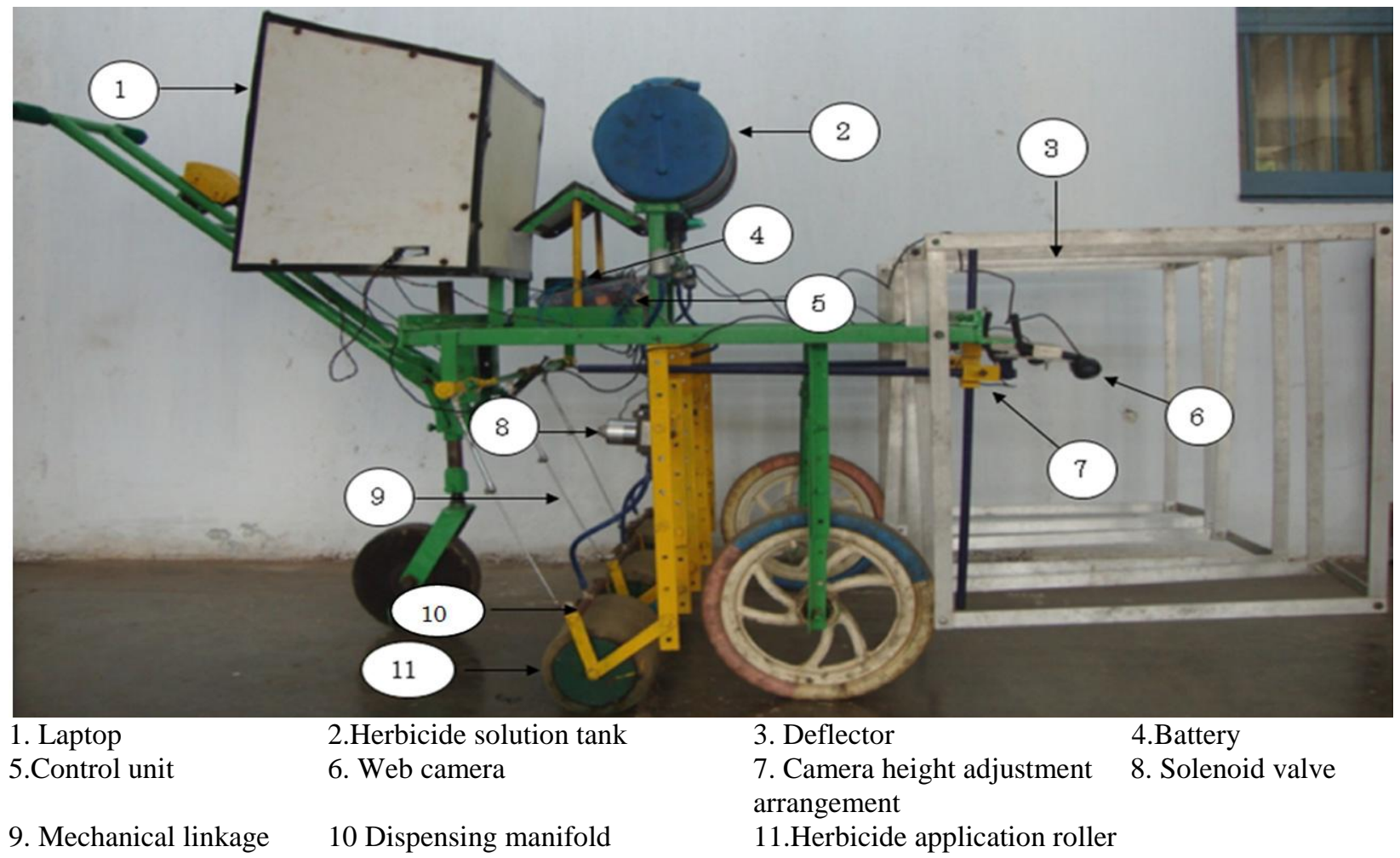
for lifting rollers

\section{References}

Esau, T. J., Zaman, Q. U., Chang, Y. K., Schumann, A. W., Percival, D. C., and Farooque, A. A. (2014). Spot- application of fungicide for wild blueberry using an automated prototype variable rate sprayer. Precision agriculture, 15(2), 147-161. 
Gonzalez-de-Soto, M., Emmi, L., Perez-Ruiz, M., Aguera, J. and Gonzalez-de-Santos, P. (2016). Autonomous systems for precise spraying-Evaluation of a robotised patch sprayer. biosystems engineering, 146, 165-182.

Loghavi, M., and Mackvandi, B. B. (2008). Development of a target oriented weed control system. Computers and electronics in agriculture, 63(2), 112118.

Midtiby, H. S., Mathiassen, S. K., Andersson, K. J., and Jørgensen, R. N. (2011). Performance evaluation of a crop/weed discriminating microsprayer. Computers and electronics in agriculture, 77(1), 3540.

ÖZLÜOYMAK, Ö. B., Bolat, A., Bayat, A., and GÜZEL, E. (2019). Design, development, and evaluation of a target oriented weed control system using machine vision. Turkish Journal of Agriculture and Forestry, 43(2), 164173.

Sabanci, K., and Aydin, C. (2018). Smart robotic weed control system for sugar beet.

Savci, S. 2012."An agricultural pollutant: chemical fertilizer." International Journal of Environmental Science and Development 3.1 (2012): 73.

Shirzadifar, A. M., Loghavi, M., and Raoufat, M. H. (2015). Development and evaluation of a real time site-specific inter-row weed management system. Iran Agricultural Research, 32(2), 3954.

Tangwongkit, R., V. M. Salokhe and H. P.W. Jayasuriya. 2006. Development of a realtime, variable rate herbicide applicator using machine vision for between row weeding of sugarcanes. The CIGR Ejournal, Manuscript PM 06009, Vol. III.

Tewari, V. K., Kumar, A. A., Nare, B., Prakash, S., and Tyagi, A. (2014). Microcontroller based roller contact type herbicide applicator for weed control under row crops. Computers and electronics in agriculture, 104, 40-45.

Thainimit, S., Muangkasem, A., Keinprasit, R., Duangtanoo, T., Tangwongkit, R., and Isshiki, T. (2012). Real-time Selective Herbicide Applicator for Field Sugarcane. Witthayasan Kasetsart (Sakha Witthayasat).

Tian, L., Reid, J. F. and Hummel, J. W. (1999). Development of a precision sprayer for site-specific weed management. Transactions of the ASAE, 42(4), 893.

Weis, M., Sokefeld, M. 2010. Detection and Identification of Weeds. In: Precision Crop Protection - the Challenge and Use of Heterogeneity. Springer, Netherlands, Dordrecht, pp. 119-134.

Yang C, Prasher SO, Landry J, Ramaswamy HS (2003). Development of an image processing system and a fuzzy algorithm for site specific herbicide applications. Precis Agric 4: 5-18.

Zaman, Q. U., Esau, T. J., Schumann, A. W., Percival, D. C., Chang, Y. K., Read, S. M., and Farooque, A. A. (2011). Development of prototype automated variable rate sprayer for real-time spotapplication of agrochemicals in wild blueberry fields. Computers and Electronics in Agriculture, 76(2), 175182

\section{How to cite this article:}

Pankaj Malkani, K. R. Asha, Atish Sagar, Abhinav Dubey, AkshayKumar Singh and Prashant Singh. 2019. A Review on Recently Developed Technologies for Weed Recognition and Herbicide Application based on Digital Image Processing. Int.J.Curr.Microbiol.App.Sci. 8(12): 589-597. doi: https://doi.org/10.20546/ijcmas.2019.812.077 